\title{
Politique
}

Politique

\section{Claude Savary (sous la direction de), Les rapports culturels entre le Québec et les États-Unis, Québec, Institut québécois de recherche sur la culture, 1984, 353 p.}

\section{Daniel Bonin}

Numéro 10, automne 1986

Opinions et votes

URI : https://id.erudit.org/iderudit/040538ar

DOI : https://doi.org/10.7202/040538ar

Aller au sommaire du numéro

Éditeur(s)

Société québécoise de science politique

ISSN

0711-608X (imprimé)

1918-6584 (numérique)

Découvrir la revue

Citer ce compte rendu

Bonin, D. (1986). Compte rendu de [Claude Savary (sous la direction de), Les rapports culturels entre le Québec et les États-Unis, Québec, Institut québécois de recherche sur la culture, 1984, 353 p.] Politique, (10), 125-129.

https://doi.org/10.7202/040538ar d'utilisation que vous pouvez consulter en ligne.

https://apropos.erudit.org/fr/usagers/politique-dutilisation/ 
Claude Savary (sous la direction de), Les rapports culturels entre le Québec et les États-Unis, Québec, Institut québécois de recherche sur la culture, 1984, $353 \mathrm{p}$.

Fruit d'un colloque organisé conjointement par l'IQRC et l'Université du Québec à Trois-Rivières, l'ouvrage reproduit l'ensemble des communications présentées à cette occasion. L'objectif majeur de la rencontre était de faire le point sur les différentes recherches accomplies jusqu'à ce jour au chapitre de nos rapports culturels avec les États-Unis.

Le volume se divise en deux grandes parties comprenant chacune des exposés portant sur divers aspects de la problématique étudiée et toutes les communications s'assortissent de commentaires (parfois discordants). Finalement le livre s'achève sur le résumé de deux tables rondes traitant de points particuliers.

Il importait d'abord de bien cerner la notion de culture; ainsi au lieu de l'entendre dans son sens le plus strict (c'est-àdire en terme de production et de consommation de biens culturels), les participants au colloque ont plutôt envisagé l'objet culturel dans une perspective de type «anthropologique» qui renvoie, selon C. Savary, à «l'ordre des normes, des valeurs, des comportements, de l'action et de l'organisation de l'existence» (p. 9).

Cela dit, l'ouvrage s'ouvre en premier lieu sur les «perspectives historiques des origines à la Deuxième Guerre Mondiale». Dans le chapitre initial, Cameron Fish s'emploie à démontrer que le destin de minoritaires dévolu actuellement aux francophones d'Amérique du Nord était, en fait, déjà inscrit dans l'ordre des choses... cent ans avant la Conquête anglaise! Fish souligne que l'absence d'une véritable politique coloniale par la France (ainsi que l'Espagne) avantagea dans les faits l'Angleterre, laquelle parvint à peupler en grande partie sa colonie américaine de réfugiés économiques et religieux. Ce qui fait dire à $\mathrm{D}$. Delage dans son 
commentaire que vers 1664, en Amérique du Nord, «l'inévitable était le domaine anglo-saxon» (p. 39).

Jean-Paul Bernard aborde quant à lui la question des «idéologies québécoises et américaines au XIX ${ }^{e}$ siècle». L'auteur privilégie alors une thèse récente dans l'historiographie québécoise suivant laquelle le libéralisme économique aurait déjà conditionné le Québec dès 1867 , puis fut relayé au tournant du siècle par un libéralisme dit «triomphant» (en raison soi-disant de son imprégnation idéologique au sein de la population). André Vachet conteste, dans son commentaire, les prémisses analytiques de Bernard et il estime pour sa part que l'influence américaine s'est limitée au Québec à, tout au plus, l'adoption d'un modèle composite de démocratie.

À un autre registre, Guildo Rousseau identifie les canaux d'expression (littérature, journaux, théâtre, etc.) par le biais desquels l'«image des États-Unis a pénétré l'imaginaire québécois. On retient notamment que les écrivains américains Fenimore Cooper et $\mathrm{H}$. L. Longfellow se sont avérés une réelle "présence libératrice» pour nos littérateurs (Marmette, Crémazie et Fréchette entre autres) au siècle dernier.

Yves Roby dans «un Québec émigré aux États-Unis: bilan historiographiques» offre un large aperçu de la littérature consacrée à ce quasi-million de Québécois qui désertèrent la province pour les états de la Nouvelle-Angleterre entre 1840 et 1930. Cibles par excellence aux États-Unis des partisans du «one hundred percent Americanism», ceux qu'on surnommait les "Chinois de l'Est» ont à un certain moment fait figure, pour les élites politiques du Québec, de symbole de la résistance francophone sur le continent. Sir A. Chapleau alla même jusqu'à qualifier les Franco-Américains de «sentinelles avancée de la patrie commune» (p. 107). Mais, à partir de 1945, l'«american way of life» a graduellement sapé les fondements institutionnels de la Franco-Américanie. Communauté menacée donc, mais certes pas dépourvue d'intérêt aux yeux 
de chercheurs comme P. Anctil qui trouve là l'occasion de «tâter un certain vécu anthropologique propre aux migrants» (p. 135).

Richard Jones conclut cette première partie en tentant de vérifier s'il existe un «spectre de l'américanisation au Québec». En fait, pour Jones, l'antiaméricanisme aura été historiquement le fait exclusif d'une certaine élite (clérico-traditionnaliste ou réformiste), la majorité de la population n'ayant, quant à elle, jamais cessé de percevoir positivement son rapport avec les États-Unis ainsi que le confirmait, voilà quelque temps déjà, un sondage Crop-La Presse.

Dans la deuxième section de l'ouvrage, l'accent est mis sur les «problèmes d'aujourd'hui» qui caractérisent la dynamique sociétale Québec/U.S.A. Il èst d'abord question de «l'arrière-plan politique et économique» propre aux deux sociétés; dans cette communication, Bruno Perron réfere à la notion d'espace pour appréhender le cadre des interrelations québéco-américaines. Eu égard à ce pattern, le Québec apparaît comme une «formation sociale" structurellement dépendante au plan économique face à son puissant voisin. Mais au-delà de sa quasi-servitude envers les États-Unis, le Québec possède tout de même les moyens d'affirmer tantôt une ouverture modeste vers d'autres partenaires économiques, tantôt la volonté de prendre en main le propre développement de ses ressources. Somme toute, Perron rappelle que le cadre futur des relations Québe-U.S.A. s'avère avant tout une question politique; il appartiendra éventuellement au "Gouvernement » provincial de faire des choix qui, peu importe leur nature, engageront le Québec pour plusieurs décennies.

De son côté, Charles H. Davis aborde le volet de «l'enseignement supérieur et (de) la recherche». L'asymétrie qu'on retrouve, selon lui, dans les relations scientifiques québéco-américaines s'expliquerait de deux manières: d'une part à cause de la prépondérance des États-Unis au niveau du know-how scientifique et technologique mais aussi en raison du peu d'attraction qu'exercent, à ce chapitre 
précis, les universités québécoises auprès des étudiants étrangers et plus spécifiquement, américains. Question de ne pas être en reste peut-être (!), les chercheurs québécois préféraient selon Davis (et jusqu'a encore récemment) davantage la destination européenne à celle des États-Unis. Donnée peut-être surprenante à première vue mais qui s'explique aisément quand on sait le poids qu'enregistrent les sciences humaines au sein de l'effectif total des universités québécoises. Somme toute le Québec, dans le but vraisemblablement d'affirmer sa pro-américanité, aura compris depuis peu l'importance de bien stimuler financièrement les initiatives de ses chercheurs par-delà le quarante-cinquième parallèle.

Après que Ronald Sutherland eut relevé les similarités et les différences existant entre les littératures du Québec et des États-Unis depuis une quinzaine d'années, André Joyal puis André Fortin font le point sur le phénomène de la «nouvelle culture» qui a laissé sa marque de part et d'autre de la frontière ces deux dernières décennies. De $\mathrm{H}$. D. Thoreau au siècle dernier, en passant par les hippies des années soixante et jusqu'aux «alternatifs» d'aujourd'hui, l'idée de contre-culture aura passablement évolué. L'associabilité qui caractérisait les hippies a fait place à une nouvelle génération de marginaux qui, désormais, acceptent de composer avec la société afin, par exemple, de démarrer une entreprise communautaire. Différemment politisés de leurs aînés les alternatifs des années quatre-vingt, qu'ils soient du Québec ou des ÉtatsUnis, ne canalisent leur engagement qu'au plan local et communautaire; au Québec spécifiquement, l'échec référendaire aura particulièrement contribué à l'émergence de cette attitude. Fortin estime enfin que l'alternative «est en train de s'institutionaliser» car, de plus en plus, la classe moyenne intègre ces nouvelles valeurs à son mode de vie.

Le texte final de Line Ross et Roger de la Garde sur «les médias et l'industrialisation de la culture» pose comme hypothèse centrale que la présence américaine s'avère «polymorphe et pla- 
nétaire». En fait précisent les auteurs, cet impérialisme culturel doit essentiellement sa suprématie à la diversité de ses modèles de production (talk-show, serial, variétés, etc.). De là la nécessité peut-être, pour tout pays soucieux de réagir à cette invasion culturelle, de produire des «contre-modèles» qui valoriseraient la richesse intrinsèque des cultures nationales en cause. Mais, en conclusion, Ross et de la Garde concèdent que la culture industrielle américaine peut compter sur un atout de taille: la "gratification" presque assurée que la masse y trouve.

Pour finir, mentionnons que le résumé des deux tables rondes organisées dans le cadre du colloque vaut essentiellement pour le point de vue (trop limité malheureusement) des universitaires américains présents à cette rencontre.

Daniel Bonin

Cégep de Saint-Laurent 